IZA DP No. 8771

The Inequality-Growth Plateau

Daniel J. Henderson

Junhui Qian

Le Wang

January 2015

Forschungsinstitut

zur Zukunft der Arbeit

Institute for the Study

of Labor 


\title{
The Inequality-Growth Plateau
}

\author{
Daniel J. Henderson \\ University of Alabama \\ and IZA \\ Junhui Qian \\ Shanghai Jiao Tong University \\ Le Wang
University of Alabama
and IZA
Discussion Paper No. 8771
January 2015 \\ IZA \\ P.O. Box 7240 \\ 53072 Bonn \\ Germany \\ Phone: +49-228-3894-0 \\ Fax: +49-228-3894-180 \\ E-mail: iza@iza.org
}

\begin{abstract}
Any opinions expressed here are those of the author(s) and not those of IZA. Research published in this series may include views on policy, but the institute itself takes no institutional policy positions. The IZA research network is committed to the IZA Guiding Principles of Research Integrity.

The Institute for the Study of Labor (IZA) in Bonn is a local and virtual international research center and a place of communication between science, politics and business. IZA is an independent nonprofit organization supported by Deutsche Post Foundation. The center is associated with the University of Bonn and offers a stimulating research environment through its international network, workshops and conferences, data service, project support, research visits and doctoral program. IZA engages in (i) original and internationally competitive research in all fields of labor economics, (ii) development of policy concepts, and (iii) dissemination of research results and concepts to the interested public.
\end{abstract}

IZA Discussion Papers often represent preliminary work and are circulated to encourage discussion. Citation of such a paper should account for its provisional character. A revised version may be available directly from the author. 
IZA Discussion Paper No. 8771

January 2015

\section{ABSTRACT}

\section{The Inequality-Growth Plateau*}

We examine the (potentially nonlinear) relationship between inequality and growth using a method which does not require an a priori assumption on the underlying functional form. This approach reveals a plateau completely missed by commonly used (nonlinear) parametric approaches - the economy first expands rapidly with a large decline in inequality, plateaus when inequality remains relatively stable, and then decreases rapidly with a large increase in inequality. This novel finding helps reconcile the conflicting results in the literature (using different parametric assumptions and datasets) and has important policy implications.

JEL Classification: $\quad$ C5, C14, O4

Keywords: inequality, growth, panel data, semiparametric

Corresponding author:

Daniel J. Henderson

Department of Economics, Finance and Legal Studies

University of Alabama

Tuscaloosa, AL 35487-0224

USA

E-mail: djhender@cba.ua.edu

\footnotetext{
* The authors would like to thank Michael S Delgado, Chris Parmeter and Chunbei Wang for their helpful comments.
} 


\section{Introduction}

The relationship between inequality and economic growth is an important yet controversial question. The classical view holds that inequality is beneficial for economic growth (e.g. Kaldor, 1995), whereas the neoclassical approach suggests that inequality plays no role in promoting economic development (see, e.g. Galor, 2011 for an excellent survey). In contrast to both views, more recent literature shows that inequality could have a long-lasting impact on economic development, and that the impact is not necessarily beneficial (e.g. Battisti et al., 2013) and could be nonlinear (Galor and Moav, 2004).

Similar to the theoretical literature, empirical studies of this issue also find mixed results. For example, while Forbes (2000) finds a positive effect of inequality on growth, supporting the classical view, Persson and Tabellini (1994) demonstrate that inequality is detrimental for the growth process. However, these studies impose a linear structure on the inequalitygrowth relationship and ignore the potential nonlinear relationship suggested by the recent theoretical literature. As noted in Henderson et al. (2012), "inclusion of non-linearities is necessary for determining the empirically relevant variables and uncovering key mechanisms of the growth process." While we could allow for non-linearity by estimating more flexible, higher-order polynomial regressions, these parametric approaches still impose strong functional form assumptions and misspecification of the relationship likely leads to inconsistent parameter estimates and hence potentially inappropriate policy prescriptions. Moreover, higher-order polynomial regressions are often shown to have undesirable "nonlocal effects" (Magee, 1998).

An alternative is to employ a non- or semi-parametric approach that relaxes functional form assumptions and let the data speak for themselves. An interesting study by Banerjee and Duflo (2003) adopts this approach based on nonparametric kernel estimation (see, e.g., Delgado et al., 2014 for other examples in growth empirics). However, they do not take into account the panel structure of the data, thereby failing to eliminate the unobserved, time-invariant heterogeneity, a potential source of omitted-variable bias (Forbes, 2000). To 
address this issue, we propose to use a nonparametric panel data method based on marginal integration to investigate the inequality-growth nexus. This approach accounts for the possible non-linearity in the panel data context without pre-specifying the functional form. Addressing this is non-trivial and we believe this is a useful exercise that could provide robust results to guide future studies in the field.

Using the data in Iradian (2005), we first statistically reject the parametric specifications commonly used in the literature. We then find strong evidence of non-linearity in the inequality-growth relationship. More importantly, we find an interesting plateau - the economy first expands rapidly with a large decline in inequality, plateaus when inequality remains relatively stable, and then decreases rapidly with a large increase in inequality. Such a pattern is completely masked by parametric approaches that impose artificial curvature. This novel result helps reconcile the conflicting results discussed above. Specifically, our finding of the three distinct types of relationships (i.e., positive, weak or no, and negative relationships) for different ranges of the values of inequality imply that empirical studies using different data (that spans a different range of the values of inequality) uncover different sections of the underlying function and hence produce the conflicting results.

Admittedly, there could be other sources of the time-varying omitted variables that may impede us from drawing definite causal inference from the current study. One solution may be to employ an instrumental variable approach. However, finding a valid instrument is nontrivial in this context, and the existing instrumental variables are often controversial. As noted in Durlauf et al. (2004), it is always possible to invalidate the instrumental approach because "growth theory is so broad and all-encompassing" (Rajan and Subramanian, 2008) and the inclusion of the instrumental variable in the growth equation could be easily justified - violation of the exogeneity assumption of an IV (see Bazzi and Clemens, 2013 for more on this issue). Moreover, dealing with the endogeneity problem, even with a valid instrument available, is difficult within the nonparametric framework. Only a few estimators in the panel data setting have been proposed in the literature and they are often difficult to implement. 
Given these concerns, we believe that our approach is particularly useful in this context because it relaxes the functional form assumptions while addressing the type of the omittedvariable bias that is considered to be particularly important in this literature.

Our results suggest the potential presence of thresholds in the inequality-growth relationship. ${ }^{1}$ Instead of employing kernel estimation, we could perhaps find similar results by using threshold regression. For example, Savvides and Stengos (2000) use a threshold regression model (Hansen, 2000) to look at the inequality-growth relationship. In their sample of 52 countries (over the period 1960-1992) they find evidence of a single break. However, they find that their results depend upon the functional form specified. In contrast, our model does not rely on a priori specification of the functional form and hence will not be subject to those specific biases. Further, with our (larger set of) data (and a slightly different problem), we envision two turning points (one at low levels and one at high levels of changes in the Gini coefficient), but it is unlikely that they would be sharp as is standard practice in the threshold regression literature. This suggests that future research may want to go along the lines of a nonparametric smooth threshold regression.

\section{Methodology}

The literature typically estimates variants of the following parametric reduced-form relationship between inequality and growth:

$$
\begin{aligned}
& G R_{i, t}=\alpha_{i}+\beta_{1} I_{i, t}+\epsilon_{i, t} \\
& G R_{i, t}=\alpha_{i}+\beta_{1} I_{i, t}+\beta_{1} I_{i, t}^{2}+\epsilon_{i, t},
\end{aligned}
$$

where $G R_{i, t}$ represents the growth rate of per capita GDP for country $i$ at time $t, I_{i, t}$ is the change in a measure of inequality, $\alpha_{i}$ are country fixed effects, allowed to be correlated with the level of inequality and $\epsilon_{i, t}$ is the idiosyncratic error term. Equation (1) assumes that

\footnotetext{
${ }^{1}$ We thank an anonymous referee for suggesting this possibility.
} 
the underlying relationship is linear, whereas Equation (2) assumes a quadratic relationship to capture potential non-linearity. It is typically assumed in Equation (2) that $\beta_{1}>0$ and $\beta_{2}<0$ (inverted-U). Equations (1) and (2) can be estimated via the within or first difference estimators (Forbes, 2000). Although popular, consistent estimates are only obtained if the functional form is correctly specified.

Given that the true relationship is generally a priori unknown, it may be best to let the data tell the form of the relationship. To this end, we consider the following nonparametric model

$$
G R_{i, t}=\alpha_{i}+m\left(I_{i, t}\right)+\epsilon_{i, t}
$$

where $m(\cdot)$ is a unknown smooth function. The presence of the fixed effects $\alpha_{i}$ creates a challenge for estimation of Equation (3). Unlike Equations (1) and (2), usual panel data estimation techniques such as first differencing cannot directly solve the problem in this context. First differencing Equation (3) results in a more complicated form

$$
\begin{aligned}
G R_{i, t}-G R_{i, t-1} & =m\left(I_{i, t}\right)-m\left(I_{i, t-1}\right)+\epsilon_{i, t}-\epsilon_{i, t-1} \\
\Delta G R_{i, t} & =g\left(I_{i, t}, I_{i, t-1}\right)+\Delta \epsilon_{i, t}
\end{aligned}
$$

Standard nonparametric estimation will allow us to recover the function $g(\cdot){ }^{2}$ Estimating $m(\cdot)$ is a non-trivial task given that it shows up twice in (4) and is evaluated at two different points (i.e., $m\left(I_{i, t}\right)$ and $\left.m\left(I_{i, t-1}\right)\right) .^{3}$

\footnotetext{
${ }^{2}$ The estimator in Qian and Wang (2012) makes the assumption that $\epsilon_{i, t}$ is i.i.d. over cross-sections (a common assumption in the panel data literature). This assumption is not restrictive and allows for arbitrary serial correlation along the time dimension. Transformations of the error term (such as the first and double differences, $\Delta \epsilon_{i, t}$ or $\Delta \epsilon_{i, t}-\Delta \epsilon_{i, t-1}$ ) possess the same property (in fact, first differencing even allows for the error in the original equation to be a random walk). That being said, differencing leads to an efficiency loss. We employ the sample augmentation technique suggested in Qian and Wang (2012) to improve finite sample performance (which has been shown to work well via simulations).

${ }^{3}$ Note that following the literature (e.g., Banerjee and Duflo, 2003), we assume that the relationship takes the form in Equation (3), instead of levels between inequality and GDP per capita (e.g., in the literature on the Kuznets Curve). The first-differencing transformation of Equation (3) is designed to recover the functional form $m(\cdot) ; g(\cdot)$ itself is generally not of interest.
} 
We propose to recover $m(\cdot)$ by marginally integrating $\widehat{g}(\cdot)$ (originally developed in the cross-sectional setting by Linton and Nielsen, 1995), a nonparametric estimate of $g(\cdot)$, which can be obtained via local-linear least-squares. Specifically, the estimator is given by

$$
m\left(I_{i, t}\right)=\int \widehat{g}\left(I_{i, t}, I_{i, t-1}\right) f\left(I_{i, t-1}\right) d\left(I_{i, t-1}\right)
$$

where $f\left(I_{i, t-1}\right)$ is a density function that satisfies $\int f\left(I_{i, t-1}\right)=1 .{ }^{4}$ Asymptotic properties of this estimator are derived in Qian and Wang (2012). In practice, we use a plug-in bandwidth that minimizes estimated asymptotic mean integrated squared error (AMISE). Our marginal integration method is carried out by first generating i.i.d. samples $I_{i, t-1}$ from the distribution $f(\cdot)$ and then we construct the estimator, $m\left(I_{i, t}\right)=\frac{1}{n} \sum_{i=1}^{n} \widehat{g}\left(I_{i, t}, I_{i, t-1}\right)$ using numerical integration. This approach is non-iterative (unlike that in Henderson et al., 2008), easy to implement in practice and has been shown to perform well in finite samples (Qian and Wang, 2012).

\section{Application}

\subsection{Data}

The data come directly from Iradian (2005) and thus we provide limited details. The data span 1965-2003 for 82 countries. Growth is measured by the annual average growth rate of GDP per capita between two survey years. Following Banerjee and Duflo (2003), we use growth rates of Gini coefficients as our measure of the change in inequality. In addition, we also use the level of changes in inequality to assess the robustness of our results.

\subsection{Specification Testing}

We formally assess the validity of the parametric functional assumptions based on the specification test developed in Hsiao et al. (2007). Our null hypothesis is that the parametric

\footnotetext{
${ }^{4}$ Following the literature, we assume that $\int \widehat{g}(\cdot) f\left(I_{i, t-1}\right) d\left(I_{i, t-1}\right)=0$. Note that this assumption is inconsequential. Even if it fails to hold, we could still identify $m(\cdot)$ up to a constant; the estimation of the shape of $m(\cdot)$, the focus of this paper, is not affected.
} 
model is correctly specified. Unlike most popular parametric tests that lack power in certain directions, this test is consistent in all directions. Given that asymptotic approximations for kernel based tests usually perform poorly in finite samples, we conduct inference based on a wild bootstrap procedure. Both the test statistics and p-values from each of our four functional form tests (linear and quadratic specifications for both the change and growth rates of inequality) are reported in Table 1 . We easily reject the null of a correctly specified parametric model at the $5 \%$ level in each case. This result implies that the nonparametric specification is preferable and failure to correctly specify the functional form could lead to misleading conclusions.

Table 1: Conditional Moment Test of Parametric Specification - Hsiao et al. (2007)

\begin{tabular}{lcccc}
\hline \hline & \multicolumn{2}{c}{ Change } & \multicolumn{2}{c}{ Growth } \\
& $\begin{array}{c}\text { Linear } \\
(1)\end{array}$ & $\begin{array}{c}\text { Quadratic } \\
(2)\end{array}$ & $\begin{array}{c}\text { Linear } \\
\text { Quadratic }\end{array}$ & $(3)$ \\
Test Statistic & 1.788 & 0.984 & 3.014 & 1.118 \\
p-value & 0.015 & 0.010 & 0.005 & 0.018 \\
\hline \hline
\end{tabular}

\subsection{Estimation}

We now turn to the estimation results. Figure 1 plots the estimated relationship between inequality and growth from both the parametric and nonparametric panel data models. We first note that these parametric results are largely consistent with the existing literature. For example, the linear model suggests that there exists a negative relationship between economic growth and inequality, consistent with Persson and Tabellini (1994); the quadratic model suggests that there is a nonlinear relationship between inequality and growth (inverted U-shape), consistent with Charles-Coll (2012). This model suggests that an economy initially grows with inequality, however, economic growth starts to decrease after inequality growth reaches a certain level. Moreover, there is little difference between parametric models (of each type), except at extreme endpoints. 
Turning to our nonparametric results, we again find evidence supporting the nonlinear relationship. However, two important departures from the parametric results emerge. First, we find the turning points in the nonlinear relationship implied by different approaches are strikingly different. While the parametric results indicate a peak around zero, our nonparametric models yield a peak much earlier. In particular, economic growth reaches its peak when the decrease in inequality is large, about 8 in terms of level or 15 percentage points. The parametric results imply that a decrease in inequality usually promotes economic growth (the positive effect exists within a much larger region of negative values). Our nonparametric results imply that such a positive effect exists only when inequality declines drastically (i.e., only for large negative values). This result has important policy implications: not all polices that reduce inequality will lead to faster economic growth. Instead, only those that greatly reduce inequality will. On the other side, pro-growth policies that also increase inequality (e.g., fiscal policies that redistribute income) may still be effective as long as the inequality increase resulted from the policies is relatively small.

Second, our nonparametric results suggest that after quickly reaching the peak, the curve remains relatively flat until a relatively large increase in inequality and then decreases afterward..$^{5}$ This result suggests that there is a range of values of changes in inequality where the link is weak. This type of relationship is difficult to obtain with parametric approaches that impose artificial curvature.

These results together help reconcile the conflicting findings in the literature using different data sets. If the data are comprised of observations from periods or countries where the Gini coefficient increases dramatically, we are more likely to observe a negative relationship between inequality and economic growth. Indeed, we generally find a negative relationship in transitional economies where inequality increases rapidly (e.g., Sukiassyan, 2007). If the

\footnotetext{
${ }^{5}$ Note that the nonparametric regression shapes implied by different inequality measures are largely similar (panels (a) and (b) versus (c) and (d) in Figure 1). The one difference is in the right-tail. If taken literally, this would suggest that (for changes in inequality) the economy expands slightly when inequality nears the maximum value. This counter-intuitive result is likely due to lack of data, evident by drastically widened confidence intervals. Note that we do not see these large differences and confidence bounds in the left-tail.
} 
data contain countries where the level is relatively stable or decreases, we are more likely to find an insignificant relationship or positive relationship. For example, Barro (2000) and Castello-Climent (2010) both find a positive relationship between inequality and growth in more advanced countries where inequality is more likely to remain stable or decrease.

In addition to the quadratic relationships, one may be attempted to use higher-order polynomial regressions with cubic or quartic terms to approximate the nonlinear relationship. However, polynomial regressions are still global functions and may not capture local anomalies. Specifically, higher-order polynomial regressions often lead to "undesirable nonlocal effects" (Magee, 1998). In the appendix (available upon request), we examine higher-order parametric models and indeed find large abnormalities, especially in both extreme tails of the distribution of inequality.

\section{References}

Banerjee, A.V. and E. Duflo. 2003. "Inequality and Growth: What Can the Data Say?" Journal of Economic Growth 8:267-299.

Barro, R.J. 2000. "Inequality and Growth in a Panel of Countries." Journal of Economic Growth 5:5-32.

Battisti, M., G. di Vaio, and J. Zeira. 2013. "Global Divergence in Growth Regressions." Unpublished Manuscript .

Bazzi, S. and M.A. Clemens. 2013. "Blunt Instruments: Avoiding Common Pitfalls in Identifying the Causes of Economic Growth." American Economic Journal: Macroeconomics $5: 152-86$.

Castello-Climent, A. 2010. "Inequality and Growth in Advanced Economies: An Empirical Investigation." Journal of Economic Inequality 8:293-321.

Charles-Coll, J. 2012. "The Optimal Rate of Inequality: A Framework for the Relationship between Income Inequality and Economic Growth." Unpublished Manuscript . 
Delgado, M.S., D.J. Henderson, and C.F. Parmeter. 2014. "Does Education Matter for Economic Growth." Oxford Bulletin of Economics and Statistics 76:334-359.

Durlauf, S., P. Johnson, and J. Temple. 2004. Handbook of Economic Growth, chapter Growth Econometrics. Amsterdam: Elsevier.

Forbes, K.J. 2000. "A Reassessment of the Relationship Between Inequality and Growth." American Economic Review 90:869-887.

Galor, O. 2011. Handbook of Economics of Education, volume 4, chapter Inequality, Human Capital Formation and the Process of Development, pp. 441-492. Elsevier.

Galor, O. and O. Moav. 2004. "From Physical to Human Capital Accumulation: Inequality and the Process of Development." Review of Economic Studies 71:1001-1026.

Hansen, B. 2000. "Sample Splitting and Threshold Regression." Econometrica 68:575-603.

Henderson, D.J., R.J. Carroll, and Q. Li. 2008. "Nonparametric Estimation and Testing of Fixed Effects Panel Data Models." Journal of Econometrics 144:257-275.

Henderson, D.J., C. Papageorgiou, and C.F. Parmeter. 2012. "Growth Empirics without Parametes." Economic Journal 122:125-154.

Hsiao, C., Q. Li, and J. Racine. 2007. "A Consistent Model Specification Test with Mixed Categorical and Continuous Data." Journal of Econometrics 140:802-826.

Iradian, G. 2005. "Inequality, Poverty, and Growth: Cross-Country Evidence." IMF Working Paper WP/05/28.

Kaldor, N. 1995. "A Model of Economic Growth." Economic Journal 67:591-624.

Linton, O. and J.P. Nielsen. 1995. "A Kernel Method of Estimating Structured Nonparametric Regression Based on Marginal Integration." Biometrika 82:93-100. 
Magee, L. 1998. "Nonlocal Behavior in Polynomial Regressions." The American Statistician $52: 20-22$.

Persson, T. and G. Tabellini. 1994. "Is Inequality Harmful For Growth?" American Economic Review 84:600-621.

Qian, J. and L. Wang. 2012. "Estimating Semiparametric Panel Data Models by Marginal Integration." Journal of Econometrics 167:483-493.

Rajan, R.G. and A. Subramanian. 2008. "Aid and Growth: What Does the Cross-Country Evidence Really Show?" Review of Economics and Statistics 90:643-665.

Savvides, A. and T. Stengos. 2000. "Income Inequality and Economic Development: Evidence from the Threshold Regression Model." Economics Letters 69:207-212.

Sukiassyan, G. 2007. "Inequality and Growth: What Does The Transition Economy Data Say?" Journal of Comparative Economics 35:35-56. 


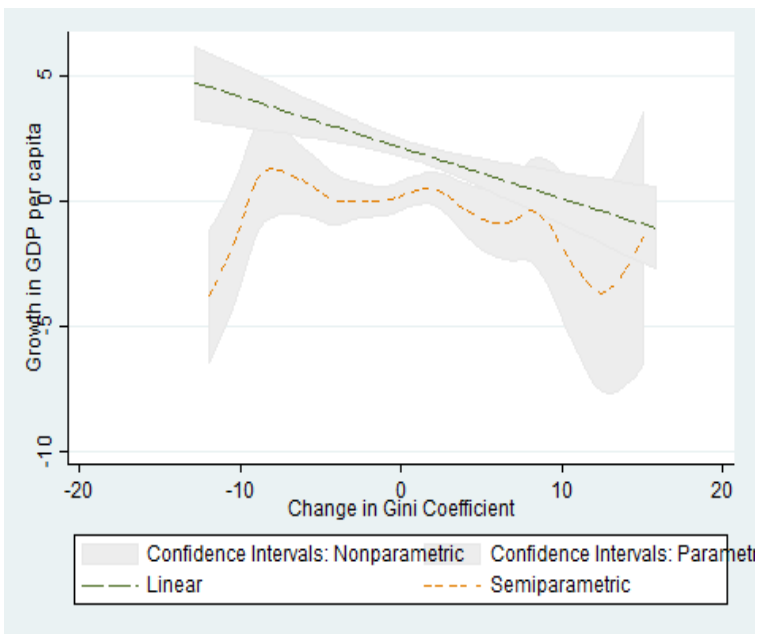

(a) Linear

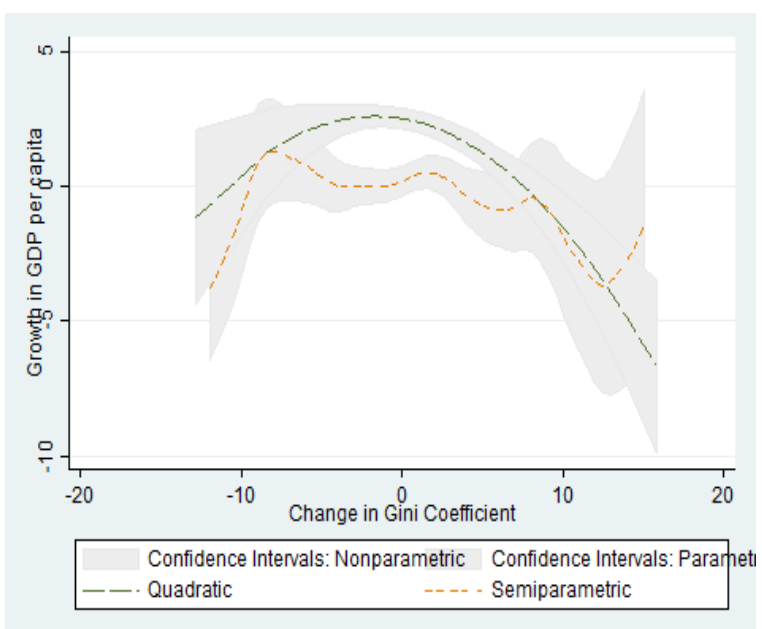

(b) Quadratic

\section{[Change]}

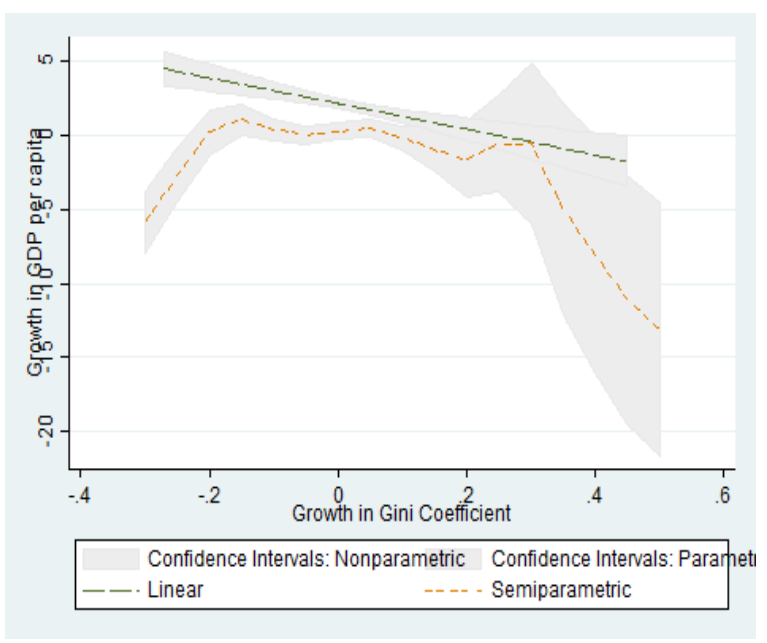

(c) Linear

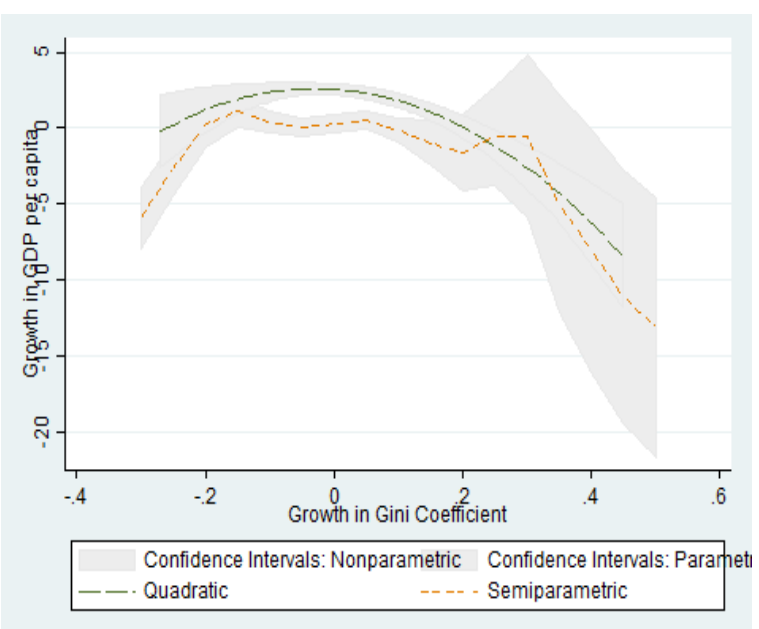

(d) Quadratic

[Growth]

Figure 1: Relationship between Inequality and Growth in GDP per capita 